\title{
Can Vessel Invasion Change the TNM Stage in Non-small Cell Lung Cancer? A Reply
}

\author{
Kazuhito Funai, PhD, MD \\ Hamamatsu University School of Medicine, Hamamatsu, Japan
}

\section{TO THE EDITORS:}

We greatly appreciate the comments from Dr. Zhang and colleagues (http://www.surgonc.org/news-publications/ann als-of-surgical-oncology/letters-to-the-editor/can-vessel-invas ion-change-the-tnm-stage-in-nsclc-) regarding our article. ${ }^{1}$ In our study, lymphatic vessel invasion (LVI) is an independent poor prognostic factor in patients with pathologic stage IA adenocarcinoma; therefore, we believe that both $\mathrm{T} 1 \mathrm{a}$ and $\mathrm{T} 1 \mathrm{~b}$ patients with LVI might benefit from adjuvant chemotherapy. The possibility that not only T1bNOM0 adenocarcinoma but also T1a with LVI will have a beneficial effect from adjuvant therapy was thus suggested. We agree with Dr. Zhang that these patients must be subjected to adjuvant chemotherapy and/or radiotherapy after surgery.

Nonetheless, we do not believe it is correct that any $\mathrm{T}$ stage with vessel invasion should be upstaged to T3 regardless of tumor size, as suggested by Dr. Zhang and colleagues. In our study, ${ }^{1}$ the 5 -year overall survival rate of the LVI-positive group was $70.9 \%$. This survival rate is the same as T1b tumors in the 7th edition of the TNM classification, but different from T3 tumors. ${ }^{2}$ Therefore, the challenge is that there are no data on the large-scale equality of prognosis for any $\mathrm{T}$ stage with vessel invasion and $\mathrm{T} 3$ tumor. $^{2}$

We believe a prospective study evaluating the survival benefit of adjuvant chemotherapy against LVI-positive T1a and $\mathrm{T} 1 \mathrm{~b}$ tumors is necessary.

\section{REFERENCES}

1. Funai K, Sugimura H, Morita T, Shundo Y, Shimizu K, Shiiya N. Lymphatic vessel invasion is a significant prognostic indicator in stage IA lung adenocarcinoma. Ann Surg Oncol. 2011;18:2968-72.

2. Goldstraw PJ, Crowley K, Chansky, et al. The IASLC Lung Cancer Staging Project: proposals for the revision of the TNM stage groupings in the forthcoming (seventh) edition of the TNM classification of malignant tumours. $J$ Thorac Oncol. 2007;2:706-14.
(C) Society of Surgical Oncology 2017

First Received: 31 October 2017;

Published Online: 27 November 2017

K. Funai, $\mathrm{PhD}, \mathrm{MD}$

e-mail: funai-oncol@umin.ac.jp 